\title{
MULTIPARTIDISMO EN EL PARLAMENTO BRITÁNICO Y REFORMA DEL MODELO WESTMINSTER ¿UN EJEMPLO (UNA SOLUCIÓN) PARA NUESTRO FUTURO SISTEMA DE PARTIDOS CON REPRESENTACIÓN PARLAMENTARIA?
}

\author{
FEDERICO DE MONTALVO JÄÄSKELÄINEN
}

Profesor Propio Adjunto de Derecho constitucional

Universidad Pontificia Comillas (ICADE)

SUMARIO

I. El resultado electoral de 2010 ¿una respuesta ciudadana adecuada a la crisis económica e institucional británica?

II. El pacto de gobernabilidad Conservadores-Liberales Demócratas ¿una respuesta política adecuada a la crisis económica e institucional británica?

III. La limitación de las competencias de disolución y control ¿El final del modelo Westminster?

IV. ¿Constituye la reforma británica un buen modelo para el posible futuro del sistema de partidos con representación parlamentaria español?

I. EL RESULTADO ELECTORAL DE 2010 ¿UNA RESPUESTA CIUDADANA ADECUADA A LA CRISIS ECONÓMICA E INSTITUCIONAL BRITÁNICA?

En el año 2010 se celebraron elecciones generales en el Reino Unido. Dichas elecciones tenían una trascendencia muy relevante que iba más allá de lo meramente político, incidiendo singularmente en el plano económico. Como puede aun perfectamente recordarse, en tales fechas la crisis económica iniciada en 2008 no sólo no se había mitigado, sino que antes al contrario, mostraba que 
sus efectos serían más duraderos de lo inicialmente esperado. La crisis, además, venía afectando de manera singular al Reino Unido, y no porque fuera precisamente una economía débil, sino porque se trataba de un modelo económico que en las últimas décadas había basado gran parte su crecimiento en el desarrollo y promoción del sistema financiero, en contraposición al modelo productivo industrial anterior. De este modo, las elecciones constituían un buen elemento de referencia para evaluar en qué medida la presumida madurez política de unos ciudadanos que pertenecían a la más antigua democracia del mundo era capaz de tomar una decisión que permitiera revertir la situación y configurar un Parlamento y Gobierno con la fortaleza de enfrentarse a los difíciles retos que planteaba la crisis ${ }^{1}$.

Pese a las dificultad y singularidad del contexto y pese a que el Reino Unido es un sistema político de partidos tradicionalmente configurado en torno a una fórmula bipartidista que tras las elecciones ha permitido conformar habitualmente gabinetes con mayoría suficiente en la Cámara de los Comunes para desarrollar su propio programa de gobierno (el último gobierno de coalición había tenido lugar más de treinta años atrás —el denominado Lib-Lab_, integrado por los Laboristas y Liberal-Demócratas con ingrato recuerdo por la crisis económica de los setenta), ninguno de los dos grandes partidos, el partido Conservador, los Tories, ni el partido Laborista, obtuvieron mayoría suficiente para formar gobierno en dichas Elecciones 2010. De este modo, las únicas alternativas eran, bien gobernar en minoría, lo que en el contexto de la crisis se presenta harto difícil, o bien recurrir al pacto con otra fuerza política.

El resultado electoral fue el siguiente:

\begin{tabular}{|l|c|c|c|}
\cline { 2 - 4 } \multicolumn{1}{c|}{} & \multicolumn{1}{c|}{$\%$ votos } & Escaños & Núm. Votos \\
\hline Conservadores & 36,1 & 307 & 10.726 .614 \\
\hline Laboristas & 29,0 & 258 & 8.609 .527 \\
\hline Liberales & 23,0 & 57 & 6.836 .824 \\
\hline Verdes & 1,0 & 1 & 285.616 \\
\hline Nacionalist Escoceses & 19,9 en Escocia & 6 & 491.386 \\
\hline Plaid Cymru & 11,3 en Gales & 3 & 165.394 \\
\hline
\end{tabular}

Como puede comprobarse a partir del análisis de dichos resultados, si bien el crecimiento en votos del Partido Liberal-Demócrata fue bastante relevante, su

1 Sobre el contexto en el que se produjeron dichas elecciones, puede verse Bogdanor, V., The Coalition and the Constitution, Hart, Oxford, 2011, pp. 1 y 2. 
traducción en votos como consecuencia del sistema mayoritario uninominal no lo fue tanto e incluso supuso un menor número que en las anteriores elecciones.

No podemos encontrar como explicación a dicho resultado electoral una única razón, sino varias. Entre tales no debe olvidarse una que no es exclusiva del Reino Unido: la crisis de las democracias y del sistema de partidos tradicional que se apreciaba en prácticamente toda Europa occidental. Además el resultado electoral podría también venir explicado por los problemas planteados por el uso irregular de recursos públicos por parte de varios miembros del Parlamento, de manera que conjuntamente con la crisis económica en el Reino Unido existía una muy importante crisis institucional. Los principales medios de comunicación británicos y, singularmente, The Daily Telegraph, habían venido publicando en los meses previos a las elecciones diferentes casos de abusos cometidos por varios miembros del Parlamento en relación a determinadas dietas y gastos de representación ${ }^{2}$.

Curiosamente, dicha crisis institucional no afectó sin embargo, en contra de lo que habían predicho algunos medios y sectores, a la participación, un $65 \%$. En las elecciones no se aprecia ni una mayor abstención, antes al contrario, la participación superó los porcentajes de 2001 y 2005, ni cambio en la distribución de los votos entre los partidos políticos, sin que el crecimiento de los partidos minoritarios o más radicales fuera muy apreciable, ni en votos, ni, menos aún, en escaños. Incluso, el Partido de los Liberales Demócratas, si bien obtuvo un mayor porcentaje de votos, perdió cinco escaños en la Cámara en comparación con las anteriores elecciones de 2005.

\section{EL PACTO DE GOBERNABILIDAD CONSERVADORES-LIBERALES DEMÓCRATAS ¿UNA RESPUESTA POLÍTICA ADECUADA A LA CRISIS ECONÓMICA E INSTITUCIONAL BRITÁNICA?}

El resultado de 2010 obligó desde el mismo día en que se conocieron los resultados a crear un pacto político de gobierno de coalición con incorporación de miembros de dos partidos al Gabinete, al no disponer ninguno de ellos de representación con una mayoría suficiente para gobernar en solitario con cierta estabilidad. Así pues, ni se optó por el gobierno en minoría ni por un mero pacto político de no confrontación. Debe recordarse que en las anteriores situaciones en las que se había producido una situación de Hung Parliament en el

2 Sobre tal escándalo, puede verse, Renwick, A., LAmb, M. y Numan, B., «The expenses scandal and the politics of electoral reform», The Political Quarterly, vol. 82, núm. 1, enero-marzo 2011, pp. 32 a 41. También, Giménez SÁNChez, I.M., «Hung Parliament y reforma constitucional en el Reino Unido», Revista General de Derecho Constitucional, núm. 10, año 2010, pp. 1 a 30; y LEYLAND, P., The Constitution of the

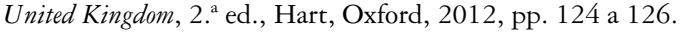


Reino Unido, la fórmula habitual no fue la del pacto de coalición, sino la del gobierno en minoría. Así ocurrió en 1910, 1923, 1929 e, incluso, en 1974³. El pacto de gobierno entre los Laboristas y los Liberales Demócratas, aunque sin incorporación de éstos al Gabinete, en la segunda mitad de los años setenta no fue la primera opción, sino que los primeros años de la legislatura del Gabinete del laborista Harold Wilson, de 1974 a su dimisión en 1976, se gobernó en minoría. No será hasta que, siendo ya Primer Ministro James Callaghan, el Gabinete tiene que enfrentarse a una moción de no confianza y entonces se formaliza dicho pacto de coalición.

Sin embargo, el contexto de 2010 era especialmente singular y tanto los Conservadores como los Laboristas eran conscientes de que la única fórmula era la del pacto de coalición, so pena de verse abocados a celebrar nuevas elecciones generales pocos meses después ${ }^{4}$. Se trataba de una situación novedosa, tanto por el mero hecho de que el pacto se produjera entre dos partidos que no lo habían celebrado anteriormente, como por la incorporación de miembros de dos partidos al Gabinete, ocupando el líder de los Conservadores la condición de Primer Ministro y el líder de los Liberales Demócratas la poco habitual de Deputy Prime Minister, que en nuestro sistema constitucional sería el Vicepresidente de Gobierno o, en términos británicos, el de Viceprimer Ministro.

El pacto se produjo finalmente, como es bien conocido, entre el Partido Conservador y el Partido Liberal Demócrata (The Coalition: Our Programme for Gover$n m e n t)^{5}$, tras el fracaso del Primer Ministro saliente, el laborista Gordon Brown, en su pretensión de anticiparse y lograr convencer a los Liberales Demócratas de Nick Clegg de las virtudes de pacto entre éstos y los Laboristas. En el pacto de gobierno finalmente alcanzado entre los Conservadores y los Liberales Demócratas ambos partidos se comprometían a impulsar diferentes reformas constitucionales de calado, algunas de ellas como fórmula para satisfacer las pretensiones de uno u otro partido para apoyar el pacto, algunas otras para transmitir cierta estabilidad de gobierno, sobre todo, en un momento tan crítico, y las últimas como expresión de voluntad de ambos partidos de regenerar el sistema político británico, conscientes de la crisis institucional en torno a la que se habían producido las elecciones.

El pacto recogía diez propuestas de reforma que afectaban, entre otras materias, al déficit económico, al gasto público, al sistema tributario, al sistema financiero, a la inmigración, pensiones, educación, relaciones con la Unión Europea y a las libertades públicas, singularmente, a la legislación sobre libertad de expresión, terrorismo y protección de datos. Finalmente, el pacto recogía una serie de propuestas de reforma política, bajo el argumento de que el sistema político es-

3 Bogdanor, V., The Coalition and the Constitution, op. cit., p. 10.

4 Ibidem, p. 11.

5 Puede accederse a dicho Pacto a través de la página web del Gobierno británico, en www.gov.uk 
taba roto, siendo urgente una reforma política, incluyendo una reforma electoral, que supusiera una mayor cooperación entre los partidos y cambios en el sistema en pro de la transparencia y rendición de cuentas ${ }^{6}$.

Las propuestas de reforma política eran cerca de treinta, con un contenido muy diferente, aunque varias de ellas se vinculaban a la necesidad de evitar futuros abusos por parte de la clase política en el uso de fondos públicos. Sin embargo, entre todas ellas pueden destacarse tres, por lo que las mismas han supuesto o podrían haber supuesto para el sistema político británico, afectando tanto al propio sistema de partidos como a la división de poderes.

La primera reforma constitucional de interés propuesta veremos que ha provocado una modificación sustancial de las competencias de disolución de la Cámara de los Comunes y convocatoria anticipada de elecciones generales. El acuerdo político entre Tories y Liberal-Demócratas, The Coalition: our programme for government, recogía el siguiente compromiso de reforma constitucional: «We will establish five-year fixed-term Parliaments. We will put a binding motion before the House of Commons stating that the next general election will be beld on the first Thursday of May 2015. Following this motion, we will legislate to make provision for fixed-term Parliaments of five years. This legislation will also provide for dissolution if $55 \%$ or more of the House votes in favour».

De recordarse, a este respecto, que la competencia de disolución de la Cámara constituye uno de los elementos clásicos de la forma de gobierno parlamentaria y que permite distinguir esta forma del modelo presidencialista en el que se establece una total separación entre el poder legislativo y ejecutivo de manera que éste no puede disolver a aquél (véase a este respecto el modelo constitucional de los Estados Unidos de América). Dicho poder de disolución tradicionalmente se considera una prerrogativa real que queda sujeta a ciertos límites derivados de las convenciones constitucionales. Entre estos límites, destaca la consulta que la Reina debe hacer a los miembros del Gabinete. Sin embargo, cuando el Gabinete dispone de mayoría suficiente en la Cámara, la Reina carece de poder efectivo de disolución, atribuyéndose éste al Primer Ministro. Se trata pues de una prerrogativa, formalmente, real que materialmente recae en el líder de la mayoría ${ }^{7}$.

La principal crítica que tradicionalmente ha recibendo en el panorama británico este poder de disolución del Primer Ministro es que permite al mismo dominar la escena política, pudiendo decidir cuándo han de celebrarse las elecciones, lo que dificulta la labor y expectativas de la oposición. Además, otorga al Primer Ministro cierto poder no sólo sobre los miembros de su propio Gabinete sino también respecto de los miembros de la Cámara de los Comunes de su propio Partido, los cuales pueden optar por no enfrentarse a determinadas decisiones

6 Véase, p. 26 del Pacto, en www.gov.uk.

7 Phillips, O. H. y JaCKson, P., Constitutional and Administrative Law, 8. ${ }^{a}$ Ed., Sweet and Maxwell, Londres, 2002, p. 343. Vid., también, LEYLAND, P., The Constitution of the United Kingdom, op. cit., pp. 93 y 94. 
de aquél, si se hace uso de la amenaza de disolución anticipada ${ }^{8}$. En todo caso, habiéndose apoyado habitualmente los dos principales partidos políticos en una mayoría suficiente para gobernar en solitario, no constituye una cuestión que hubiera planteado excesivo debate ni doctrinal ni político, salvo para los partidos minoritarios, como el Liberal Demócrata, aunque es cierto que el Partido Laborista incluyera dicha propuesta en un Manifiesto de 1992 e incorporada formalmente la fórmula de Fixed-term al Parlamento escocés y la Asamblea de Gales a través de las políticas de devolution of powers ${ }^{9}$.

Frente a las críticas que tradicionalmente recibía el poder que tenía el Primer Ministro en cuanto a fijar la fecha de las elecciones, algún autor ha planteado que dicha facultad del Primer Ministro refuerza la labor de la oposición, ya que la posibilidad de que las elecciones sean convocadas en cualquier momento por el Primer Ministro supone un incentivo de actuación constante ${ }^{10}$.

La reforma afecta igualmente al correlativo poder de la Cámara de los Comunes de control y, en su caso, cese del Gabinete, en la medida que dificulta notablemente la virtualidad de la moción de no confianza, incorporando la exigencia de una mayoría extraordinariamente reforzada.

Esta reforma constitucional a la que nos venimos refiriendo sí se ha traducido en una norma jurídica que ya ha entrado en vigor, Fixed Term Parliaments Act, 2011. La reforma es, en gran parte, una respuesta constitucional al cambio en el sistema de partidos y a la desaparición tras las elecciones de 2010 de un partido con suficiente mayoría parlamentaria para gobernar en solitario.

La segunda reforma afectaba al sistema electoral y pretendía sustituir el modelo mayoritario por un modelo de voto alternativo. La reforma consistía sustancialmente en modificar el sistema electoral mayoritario con circunscripción uninominal por un sistema denominado de voto alternativo (Parliamentary Voting System and Constituencies Act 2011). Esta reforma se mostraba congruente con la anterior, en la medida que potenciaba una mayor representatividad de los partidos minoritarios y la desaparición o, al menos, mitigación de los instrumentos electorales que ofrecían una sobreprima de representación a los partidos mayoritarios. Si la primera reforma pretendía dotar de mayor estabilidad política al gobierno de coalición surgido de las elecciones de 2010 y a los que pudieran surgir en el futuro, limitando la facultad del Primer Ministro de disolver la Cámara de los Comunes, esta segunda pretendía consolidar, a través de la reforma del sistema electoral, una mayor desconcentración del voto y una mayor represen-

8 Vlachogiannis, A, «The Fixed-term Parliaments Act of 2011: a model for reform of Greek parliamentarism?», pp. 6 y 7. Puede accederse a dicho trabajo a través de la página web www.constitutionalism.gr

9 Vid. House of Lords, Fixed-term Parliaments Bill. Report with evidence, HL Paper 69, 16 de diciembre de 2010, p. 7. Puede accederse a dicho documento a través de la siguiente dirección de internet: http://www. publications.parliament.uk/pa/ld201011/ldselect/ldconst/69/6906.htm

10 Hamlin, A., «Fixed-Term Parliaments: Electing the Opposition», Politics, vol. 30, núm. 1, año 2010, p. 23. 
tación de partidos minoritarios. Se trataba, pues, de dos reformas que iban de la mano, aunque si bien la primera se mostraba como una respuesta a la presunta inestabilidad de un gobierno de coalición en tiempos económicamente tan convulsos, la segunda abría ya el camino para que lo que, habiendo podido ser fruto de un contexto de crisis económica e institucional, fuera ya posible en el futuro de manera menos excepcional, al dificultarse que uno de los dos grandes partidos accediera a la mayoría absoluta.

La reforma daba cuerpo a una antigua aspiración de los partidos políticos del Reino Unido, sobre todo, de los minoritarios y de los mayoritarios mientras han ocupado los bancos de la oposición, para modificar el sistema electoral y avanzar en fórmulas de mayor proporcionalidad. La reforma fue inicialmente impulsada por el Laboristas con el apoyo de los Liberales Demócratas antes de las elecciones generales de 2010 y fue retomada por los Conservadores como exigencia para alcanzar el acuerdo político que dio lugar al actual gobierno de coalición, ya que los Liberales Demócratas han sido tradicionalmente los más castigados por el sistema electoral mayoritario.

Sin embargo, sometida a consulta popular dicha propuesta a través de un referéndum celebrado el 5 de mayo de 2011, el resultado fue contrario, alcanzando los noes un porcentaje próximo al setenta por ciento de los votos emitidos. Parece que dicho resultado, algo sorprendente en cuanto a que la reforma parecía venir apoyada por los dos partidos que sostienen al gobierno de coalición, vino motivado no sólo porque el apoyo de los Conservadores fuera más formal que real, sino además porque el sistema que se proponía como alternativa al vigente resultaba algo complejo, habiendo optado los ciudadanos británicos por la sencillez y claridad del sistema mayoritario y no por la proporcionalidad en el resultado. Puede que algo tuviera que ver con ello también la crisis económica, ya que en dicho contexto existía el riesgo de una futura Cámara, si bien más proporcional en la traducción de votos en escaños, también más fragmentada y, por tanto, más alejada de la posibilidad de formar gobiernos estables. Parece que se materializó aquello que el Primer Ministro Disraeli dijera muchos atrás, en 1852, siendo Ministro de Hacienda de que «England does not love coalitions».

La tercera reforma pretendía revisar las circunscripciones electorales, reduciendo éstas de 650 a 600, con la consiguiente reducción de escaños y MPs en la Cámara de los Comunes (Electoral Registration and Administration Bill). Dicha reforma obedece a claros motivos económicos, a diferencia de la anterior. Así, en declaraciones del Primer Ministro a los medios de comunicación, éste manifestó, literalmente, que «we should have fewer MPs to cut the cost of politics, and more equal size constituencies so that people's votes have more equal weight».

Esta reforma tiene diferente significado que las dos anteriores y no puede encuadrarse en un mismo marco de reformas, ya que la reducción de escaños produce necesariamente una menor representación de los grupos minoritarios en el Parlamento. Por ello, se trata de una propuesta de reforma que trae causa de las exigencias que parecen derivarse de la crisis económica y del incremento del gas- 
to público que en otros Estados se ha traducido, bien en la reducción de escaños en la Cámara Baja, bien en la supresión de la Cámara Alta.

Sin embargo, dicha reforma se ha encontrado con el veto de la Cámara de los Lores que ha rechazado tal propuesta, cuya entrada en vigor efectiva estaba prevista para las siguientes elecciones generales en mayo de 2015. Tal veto no determina que la reforma necesariamente decaiga, pero sí que la misma haya de retrasarse de manera que ya no es posible que pueda entrar en vigor en las próximas elecciones.

Las razones de dicho veto podría encontrarse en el hecho de que la reforma pudiera favorecer los intereses del Partido Conservador, provocando en las elecciones generales de 2015 un incremento de hasta veinte escaños para dicho partido. Si recordamos que tradicionalmente los expertos han considerado que la actual división territorial del sistema electoral ha beneficiado a los Laboristas, no es difícil adivinar que precisamente han sido los Lores Laboristas los que han actuado en contra de dicha reforma, a los que se han unido los Liberales Demócratas, éstos últimos al no ver satisfecha su pretensión de reformar también la Cámara de los Lores, respecto de lo que no encontraron apoyo de los Conservadores, y al frustrarse su propuesta de reformar el sistema electoral mediante una fórmula más proporcional.

En definitiva, son varias las reformas constitucionales de calado que se han propuesto en el Reino Unido en estos casi ya cuatro años de legislatura, aunque entendemos que nuestro análisis debe centrarse en la primera de las reformas citadas, y no sólo porque sea la única reforma que efectivamente ha prosperado, sino además porque es la que pudiera tener alguna relevancia para un futuro escenario del sistema de partidos español, que puede venir marcado, como ha ocurrido en el Reino Unido, por la pérdida de votos de los dos grandes partidos y el incremento para partidos hasta ahora minoritarios que pueden convertirse en las próximas elecciones en indispensables para formar un gobierno con apoyo parlamentario.

\section{LA LIMITACIÓN DE LAS COMPETENCIAS DE DISOLUCIÓN Y CONTROL ¿EL FINAL DEL MODELO WESTMINSTER?}

Al amparo del pacto de gobernabilidad alcanzado entre los Conservadores y los Liberales-Demócratas, se propuso, entre otras iniciativas, la de dotar al gabinete de una estabilidad difícil de alcanzar en un gobierno de coalición. Ello vino motivado tanto por la pretensión de ambos partidos de fortalecer al pacto, de manera que no fuera fácil de resolver por ninguna de las dos partes, como por la firme pretensión de trasladar al sistema económico una imagen de estabilidad, necesaria para poder afrontar las reformas que en esos momentos necesitaba la economía británica.

En todo caso, dicha reforma debe ser entendida como una concesión a los Liberales Demócratas que tradicionalmente han sido contrarios al poder de que 
disponía el Primer Ministro de disolver la Cámara. Así, ya en la anterior legislatura, dicho Partido había presentado una proposición de Ley en este mismo sentido, bajo un título idéntico, Fixed Term Parliaments Bill 2007-2008 ${ }^{11}$. Dicha proposición fue rechazada por los Comunes.

En culminación del acuerdo entre conservadores y liberal-demócratas, se aprobó la primera de las principales medidas constitucionales derivadas del pacto, la cual fue el Fixed-Term Parliaments Act de 2011. Veremos, en todo caso, que la norma finalmente aprobada cambia parcialmente el contenido del acuerdo, tanto en lo que se refiere a la mayoría que se exigirá para una disolución anticipada como a los supuestos en los que cabe tal disolución.

Esta reforma ha supuesto una limitación de la posibilidad de convocar anticipadamente elecciones a la Cámara de los Comunes, bien sea por decisión del Primer Ministro al amparo de su facultad de disolver la Cámara, o bien sea por decisión de la propia Cámara al acordar una moción de censura frente al Gabinete. Así pues, es una fórmula encaminada a dar estabilidad a un gobierno que necesita el apoyo de dos partidos en el Parlamento.

Sin embargo, el contexto de crisis económica provocó que lo que se mostraba como infrecuente en el modelo político británico fuera también peligroso por el riesgo de inestabilidad. Los gobiernos de coalición constituyen una figura extraña en el sistema político británico, y no sólo por la tradicional existencia de dos grandes partidos, sino fundamentalmente por el propio sistema electoral que, siendo mayoritario y con circunscripción uninominal, provoca una sobrerrepresentación del Partido más votado al basarse en la fórmula first past the post.

Por todo ello, tal reforma constitucional creemos que es especialmente trascendente para nuestro propio entorno jurídico-constitucional. Y ello, no sólo porque se produce en la más antigua democracia moderna, a la que habitualmente se mira con interés cuando se proponen reformas constitucionales, ni tampoco porque afecte directamente a lo que constituye uno de los instrumentos básicos en la forma de gobierno parlamentaria, como es la moción de censura. La reforma británica puede ser de interés en un futuro si el sistema político de partidos en España se ve efectivamente alterado, pasando de un modelo claramente bipartidista a un modelo con una presencia de, al menos, cuatro partidos con un porcentaje de votos superior al diez por ciento a nivel nacional y en el que, por tanto, puede ser difícil que los dos partidos tradicionalmente más votados obtengan una mayoría suficiente para gobernar en solitario, como frecuentemente ha ocurrido en nuestra actual democracia.

11 En el debate sobre esta proposición, los miembros de la Cámara que defendieron dicha iniciativa compararon dicha prerrogativa con entregar a uno de los participantes en una carrera de cien metros la pistola, pudiendo emplearla no sólo para marcar el inicio de la misma a su antojo, sino también para disparar a otro de los participantes (intervención de David Howarth en la segunda lectura de la proposición en la Cámara de los Comunes, el 16 de mayo de 2008). 
La reforma constitucional británica pretende dar gran estabilidad al Gobierno de coalición durante los cinco años de legislatura de manera que la posibilidad de que el Parlamento pueda recurrir a la moción de censura, lo que, lógicamente, ocurriría si se rompiera el acuerdo político en el que se sustenta la coalición, se dificulta $^{12}$. Igualmente, se elimina la posibilidad de que el Primer Ministro pueda ejercer su facultad de disolución anticipada de la Cámara y de convocatoria anticipada de elecciones.

La nueva Ley aprobada en el Reino Unido en 2011 declara que las próximas elecciones se celebrarán el 7 de mayo de 2015 (Art. 1.2). El mismo periodo de cinco años se fija para las subsiguientes elecciones generales (Art. 1.3).

Por tanto, de ello cabe concluir que la regla general es la de convocatoria cerrada de elecciones cada cinco años, sin posibilidad de convocatorias anticipadas, bien a voluntad del Parlamento, por haber perdido el Gabinete la confianza, bien por decisión del Primer Ministro.

Sin embargo, la Ley establece dos excepciones a esta regla general, en virtud de las cuales, se permitiría una elección anticipada. Estas excepciones se consideran como una especie de válvula de escape para evitar los problemas que pudieran derivarse de una fórmula absolutamente cerrada. Como señalara la Cámara de los Lores en su evaluación del proyecto de Ley: «We conclude that it is sensible for the Bill to contain some form of safety valve which would allow for an early election in circumstances such as the government losing the confidence of the Commons or where a political or economic crisis has affected the country. Such circumstances cannot be identified nor listed in advance and so the safety valve(s) chosen must be sufficiently flexible to deal with the various situations which might arise» ${ }^{13}$.

Como puede verse, dicha Cámara se muestra a favor de una fórmula abierta en la que quepan varios supuestos de hecho, en lugar de describir diferentes situaciones específicas al amparo de las cuales se admitiera el adelanto electoral.

Las dos excepciones son las siguientes:

En primer lugar, si la Cámara de los Comunes aprueba una moción para la celebración de elecciones anticipadas por mayoría de, al menos, dos tercios de sus miembros (la Ley añade que incluidos los escaños vacantes ${ }^{14}$. La Ley establece de manera expresa que formalmente la moción deberá expresarse en los siguientes términos: "That there shall be an early parliamentary general election» (art. 2.2).

12 La reforma no ha cambiado la duración de la legislatura que tras el Parliaments Act de 1911 se estableció en cinco años frente al periodo de siete años que se recogía en la Septenial Act de 1715.

13 Vid. House of Lords, Fixed-term Parliaments Bill. Report with evidence, HL Paper 69, 16 de diciembre de 2010, p. 25. Puede accederse a dicho documento a través de la siguiente dirección de internet: http://www. publications.parliament.uk/pa/ld201011/ldselect/ldconst/69/6906.htm

14 Inicialmente se ha había propuesto una mayoría de un cincuenta y cinco por ciento de los miembros de la Cámara, pero pronto se consideró que dicha mayoría no permitía restringir de una manera efectiva la facultad del Primer Ministro de convocar anticipadamente elecciones. La mayoría de dos tercios responde a una propuesta de Nick Clegg, habiendo tomado como referencia el modelo escocés. 
Se trata, pues, como puede apreciarse, de una mayoría muy reforzada que evitaría que la disolución anticipada fuera acordada indirectamente por el Primer Ministro a través de la mayoría parlamentaria que le sostiene en el Gabinete. Tal mayoría exigiría, en todo caso, un acuerdo entre varias fuerzas políticas, sin que la suma de escaños de la actual coalición de gobierno alcance dicho número.

Puede comprobarse, igualmente, que la mayoría es superior a la inicialmente mencionada en el pacto de gobernabilidad suscrito entre los Conservadores y los Liberales Demócratas, el cincuenta y cinco por ciento, aunque el propio pacto añadía que «or more of the House votes in favour». La opción de una mayoría de dos tercios en lugar de la mayoría del cincuenta y cinco por ciento obedece fundamentalmente a las críticas que dicho porcentaje inicial recibió tanto por parte de los partidos de la oposición como de los medios de comunicación, ya que en modo alguno eliminaba el poder, no del Primer Ministro, sino de la coalición de disolver la Cámara y anticipar elecciones, ya que la suma de escaños de los partidos que alcanzaron el pacto sí llegaba a dicho porcentaje del cincuenta y cinco por ciento $^{15}$.

En segundo lugar, si la Cámara de los Comunes aprueba una moción de no confianza en el Gabinete ("That this House has no confidence in Her Majesty's Government», art. 2.4) y transcurren catorce días sin que se apruebe una moción de confianza en el mismo o en otro Gabinete. En esta modalidad no se exige mayoría reforzada, lo que facilitaría el recurso a la moción de censura, pero exige un periodo de tiempo que permitiera alcanzar un nuevo acuerdo de gobierno sin necesidad de convocar elecciones anticipadas, lo que podría venir provocado por la presión de la opinión pública. En todo caso, podemos considerar que la fórmula adoptada con la reforma es una fórmula flexible en lo que se refiere a las facultades de la Cámara de los Comunes, ya que si bien la exigencia de una mayoría de dos tercios prácticamente hace inviable que una moción de censura pueda tener éxito, la segunda excepción parece dejar bastante intactas dichas facultades. Ello probablemente obedece a que varios expertos se pronunciaron en contra de la reforma aprobada en los trámites previos de elaboración de la misma y, singularmente, Vernon Bogdanor ${ }^{16}$. Por ello, se optó, no por la práctica supresión del poder del Parlamento de cesar al Primer Ministro y su Gabinete, sino por meramente limitar o dificultar el ejercicio de dicha competencia.

En el informe elaborado por la Comisión Constitucional de la Cámara de los Lores acerca de dicho proyecto de Ley se señala que el contexto que podría poner en juego cada una de estas dos excepciones es diferente: mientras que la primera fór-

15 Vid. House of Lords, Fixed-term Parliaments Bill. Report with evidence, HL Paper 69, 16 de diciembre de 2010, p. 26. Puede accederse a dicho documento a través de la siguiente dirección de internet: http://www. publications.parliament.uk/pa/ld201011/ldselect/ldconst/69/6906.htm

16 También Alan Hamlin se mostró en contra de establecer una fórmula de fixed-term al considerar que ello debilitaba a la oposición, ya que la posibilidad de convocatoria anticipada de elecciones estimula una mejor labor de la oposición. 
mula tendría cabida en aquellos casos en los que existe un acuerdo entre varios partidos acerca de la conveniencia de convocar una elección anticipada, la segunda es probable que se presente cuando exista una situación de gran disputa política ${ }^{17}$.

Sin perjuicio de ello, y como se discutió durante los trabajos de elaboración de la norma, la segunda alternativa podía ser fácilmente manipulada por la coalición de gobierno, ya que nada parece impedir que la mayoría parlamentaria que sostiene al gobierno de coalición no decida, a petición del propio Primer Ministro, plantear una especie de automoción, como ocurriera, por ejemplo, durante la legislatura del Parlamento alemán bajo la cancillería de Gerhard Schroeder. Por ello, se ha planteado que una interpretación conjunta de ambas excepciones permite concluir que, si bien la mayoría que sostiene al Gabinete sí puede y, por el porcentaje exigido, debe participar en el primer supuesto de disolución anticipada, no podría hacerlo en el segundo, de manera que éste quede limitado a su uso por parte de la oposición o de las minorías. Sin embargo, esta interpretación determina que cualquiera de las dos excepciones quede, a la postre, sin virtualidad práctica alguna, la primera por exigir una mayoría tan reforzada que ni la oposición ni el partido o, en el contexto actual, partidos en el poder puedan alcanzarla, y la segunda porque difícilmente en un contexto en el que dos partidos ocupan el Gabinete, la oposición, aun contando con las minorías, pueda alcanzar la mayoría de votos en la Cámara.

Otro problema que ha planteado esta segunda excepción es el de qué se entiende por moción de no confianza en el Gabinete de su Majestad, ya que, de acuerdo con las convenciones, existen determinados votos en contra del Gabinete que, sin expresarse en términos literales como mociones de confianza o no confianza en el Gabinete, han producido los efectos constitucionales de éstas. A este respecto, recuérdese que el régimen de las mociones no está regulado por el Derecho estatutario, sino por las convenciones, lo que dota al sistema de mayor flexibilidad pero también de mayor inseguridad, ya que pueden existir diferentes mociones que sin ser estrictamente de no confianza han producido en la historia del parlamentarismo británico los mismos efectos que una moción de no confianza. Habitualmente, se considera que, si bien no existe una definición estatutaria de tales mociones, sí que gozan de determinadas características que permitirían identificarlas. Tales características vienen referidas tanto al tiempo como a los oradores y participantes y, sobre todo, los términos de la moción.

En lo que se refiere al tiempo, cuando tiene lugar un debate que pueda afectar a la confianza en el Gabinete, tal debate tendrá prioridad sobre el resto de actividades de la Cámara. En cuanto a la participación de los oradores, en una moción de estas características, tienen participación directa en los debates tanto el Primer Ministro como el líder de la oposición, con preferencia a otros miembros del Ga-

17 Vid. House of Lords, Fixed-term Parliaments Bill. Report with evidence, HL Paper 69, 16 de diciembre de 2010, p. 26. Puede accederse a dicho documento a través de la siguiente dirección de internet: http://www. publications.parliament.uk/pa/ld201011/ldselect/ldconst/69/6906.htm 
binete o a los correspondientes responsables gubernamentales o de la oposición respecto de un determinado área de actividad. Por último, una moción de confianza por lo general incluye términos como «confianza» o «censura», o, en su caso, venir referida a un tema de gran importancia política para el Gabinete ${ }^{18}$.

En definitiva, con independencia de tales dificultades, la Ley suprime la facultad del Primer Ministro de disolver la Cámara y convocar elecciones anticipadas, de manera que cualquier convocatoria anticipada habrá de contar con el visto bueno de la Cámara, y también limita la facultad de ésta de derrocar al Gabinete a través de la moción de censura agravando los requisitos para el éxito de la misma. Como expresa literalmente Peter Leyland, la reforma «could be regarded as being a way of cementing the coalition agreement ${ }^{19}$. Sin embargo, puede quedar abierta la posibilidad de que el propio Gabinete anticipe las elecciones mediante la presentación de una auto moción de no confianza, aunque, como hemos señalado, la doctrina presenta dudas acerca de la virtualidad constitucional de dicha alternativa.

La fórmula que incorpora el sistema constitucional británico se ha inspirado tanto en el modelo que existe en Escocia, Gales e Irlanda del Norte como en otros modelos de Derecho comparado, singularmente, Noruega, donde son habituales los gobiernos de coalición.

Por lo que se refiere a Escocia, Gales e Irlanda del Norte, en todos ellos impera la regla del fixed term, de manera que las elecciones generales se celebran cada cuatro años, con un régimen excepcional de disolución anticipada ${ }^{20}$. Las dos excepciones que se establecen respecto de la regla general son prácticamente idénticas a la que recoge el nuevo Act de 2011 del Parlamento británico: bien una mayoría reforzada de dos tercios que acuerda anticipar las elecciones, bien el transcurso de un periodo de tiempo de veintiocho días, catorce días más que en la fórmula británica, sin que se consiga designar por la Cámara a un nuevo Primer Ministro tras una moción de no confianza contra el Primer Ministro en el cargo aprobada sin un régimen especial de mayoría. En el caso de que se celebren elecciones anticipadas, el nuevo parlamento electo lo será para el resto de legislatura que faltara para alcanzar los cuatro años, salvo que dichas elecciones extraordinarias hayan tenido lugar dentro de los seis meses previos a la fecha prevista para las siguientes elecciones generales, en cuyo caso se considerará que inicia una nueva

18 Véase el informe bajo el título Confidence Motions, elaborado por Richard Kelly para la Cámara de los Comunes en fecha 13 de mayo de 2013 (páginas 4 y 5). Puede accederse a dicho informe, a través de la página de la Cámara de los Comunes, en www.parliament.co.uk

19 Leyland, P., The Constitution of the United Kingdom, op. cit. p. 160.

20 La prevision contenida en el Act que establecía que las próximas elecciones a la Cámara de los Comunes se celebrarían en mayo de 2015 provocaba que dichas elecciones coincidieran con las establecidas para el Parlamento escocés y la Asamblea de Gales. Por ello, se recogió en el propio Act una prevision por la que el mandato de estas dos Cámaras se extendía hasta los cinco años, habiéndose de celebrar las siguientes elecciones en 2016 y no en 2015, evitándose así los recelos provocados en Escocia y Gales ante la posibilidad de coincidir sus elecciones con las del Parlamento británico. Curiosamente, una vez transcurridas las elecciones en 2016 el mandato del Parlamento escocés y de la Asamblea de Gales sería nuevamente de cuatro años. 
legislatura, por lo que ésta puede, en tal supuesto, superar los cuatro años, aunque nunca superar los cuatro años y seis meses.

En el caso de Noruega la fórmula es singular porque no prevé ninguna excepción a la regla general. En alguna ocasión se ha propuesto incluir una excepción que permitiera anticipar las elecciones cuando lo solicita una mayoría muy reforzada de la Cámara, pero ello tal posibilidad todavía no se ha plasmado en ninguna reforma constitucional.

La nueva fórmula ha recibido una valoración distinta por parte de la doctrina. Así, se ha señalado que si bien permite al Gabinete adoptar políticas a medio y largo plazo, aun cuando no cuente con una mayoría suficiente en la Cámara y haya tenido que recurrir a la fórmula del gobierno de coalición, presenta como principal problema el que se pierde flexibilidad y la también la posibilidad de que el Gabinete puede rendir cuentas anticipadamente sin necesidad de esperar a la siguiente convocatoria de elecciones generales ${ }^{21}$.

Además, también se ha señalado que desde la perspectiva de Derecho comparado, las fórmulas que encorsetan la legislatura a un tiempo determinado, con difícil finalización anticipada, se han mostrado bastante ineficaces. Los gobiernos han sido capaces, habitualmente, de eludir el requisito de duración determinada y convocar elecciones de acuerdo con sus intereses ${ }^{22}$. En aquellos sistemas en los que tal alternativa es prácticamente imposible, como ocurre, por ejemplo, en los Estados Unidos, acaba por producirse un peligroso bloqueo del sistema político por falta de solución a una crisis política ${ }^{23}$.

Se trata, en todo caso, de una reforma de gran calado constitucional que altera la naturaleza del parlamentarismo británico ${ }^{24}$, siendo la moción de confianza y no confianza, como ha declarado la propia Cámara de los Comunes, los dos instrumentos procedimentales más importantes del modelo Westminster ${ }^{25}$.

21 Hazell, R., «Fixed term parliaments», The Constitution Unit, University College London, agosto 2010 , p. 5 .

22 Veáse el ejemplo de Gerald Schroeder en Alemania, cuando acudió a la moción de confianza como instrumento para disolver el Bundestag y convocar anticipadamente elecciones generales, poder que no le confiere la Ley Fundamental de Bonn.

23 Véase el problema del lame duck en el sistema político norteamericano, expresión con la que se alude al Presidente que por no poder renovar su mandato al estar agotando ya su segundo mandato, decide, bien hacer atropelladamente todo aquello que no ha llevado a cabo en los años anteriores, bien tomar decisiones basadas en su propio interés personal o de partido (el ejemplo de John Adams y los midnight judges es paradigmático y fue el que dio precisamente lugar a la conocida Marbury v Madison 1803).

24 Algún autor, sin embargo, considera que dicha reforma no tiene tal trascendencia constitucional y se trata de un mero cambio más de un sistema constitucional como el británico que se reelabora paso a paso. Así, Young señala que «The UK's constitution has evolved over time, building on and replacing the 'old timbers' of statutes, common law, conventions, non-legally enforceable rules, prerogative powers, practices and principles that make up our more loosely constructed (and some would argue leaking) constitution. In one sense, the recently enacted Fixed-Term Parliaments Act 2011 is a small timber replacement». Vid. YOuNG, A., «Fixed-Term Parliaments and Neurath's Ship», 2011. Puede accederse a dicho artículo a través de la página wen, www.ukconstitutionallaw.org.

25 Turpin, C., British Government and the Constitution, 5. ${ }^{a}$ Ed., Butterworths, Londres, 2002, p. 487. Véase, también, el informe Confidence Motions, elaborado por Richard Kelly para la Cámara de los Comunes en 
En todo caso, no debe olvidarse que dicha reforma queda sujeta a una reevaluación en 2020. El mismo Act prevé en su Sección 7 que el Primer Ministro habrá de conformar entre junio y noviembre de 2020 una comisión, integrada principalmente por miembros del Parlamento, que evalúe los efectos producidos por la norma y formule las correspondientes propuestas. Esta previsión de revisión se incorporó mediante una tardía enmienda ante los recelos de los Lores al cambio que dicha norma suponía en el modelo constitucional británico, habiendo éstos propuesto que el Act fuera ratificado por cada nuevo Parlamento entrante. El acuerdo entre los Comunes y los Lores para salvar dicha propuesta de éstos últimos que los Comunes no querían aceptar concluyó con dicha propuesta de revisión en $2020^{26}$.

Algunos autores han apuntado que dicha reforma no responde a un nuevo modelo parlamentario sino a una necesidad que surge al amparo de la coalición de gobierno de manera que ante un futuro escenario de gobierno de mayoría su necesidad habrá de decaer ${ }^{27}$. El debate acerca de la reforma no ha cesado ni académica ni parlamentariamente. El pasado 23 octubre de 2014, se desarrolló un debate en una Comisión de la Cámara de los Comunes al amparo de una propuesta presentada por un grupo de parlamentarios conservadores que planteaba la conveniencia de eliminar el Act («That this House believes that the Government should bring forward proposals to repeal the Fixed-term Parliaments Act 2011»). La moción fue finalmente rechazada por sesenta y ocho votos frente a veintiuno ${ }^{28}$.

\section{IV. ¿CONSTITUYE LA REFORMA BRITÁNICA UN BUEN MODELO PARA EL POSIBLE FUTURO DEL SISTEMA DE PARTIDOS CON REPRESENTACIÓN PARLAMENTARIA ESPAÑOL?}

Los estudios de intención de voto que vienen realizándose en nuestro país en los últimos años sugieren que la posibilidad de que se reproduzca no sólo la actual mayoría absoluta del Partido Popular, sino también la que disfrutó el Partido Socialista Obrero Español en los años ochenta puede ser ya historia pasada.

fecha 13 de mayo de 2013 (página 3). Puede accederse a dicho informe, a través de la página de la Cámara de los Comunes, en www.parliament.co.uk

26 Kelly, R., Gay, O. y White, I., Fixed-term Parliaments Act 2011, SN/PC/6111, 16 de octubre de 2014 , p. 5. Puede accederse a dicho informe, a través de la página de la Cámara de los Comunes, en www. parliament.co.uk

27 Vid. The role and powers of the Prime Minister: The impact of the Fixed-term Parliaments Act 2011 on Government, House of Commons Political and Constitutional Reform Committee, Fourth Report of Session 2013-14, p. 9.

28 Dicho debate ha dado lugar a una interesante controversia constitucional acerca de los efectos que el Act ha producido sobre la anterior prerrogativa real de disolución de la Cámara y de convocatoria anticipada de elecciones generales, de manera que se discute si la mera derogación del Act provoca o no automáticamente la reinstauración de la prerrogativa. 
Tanto la crisis económica como la crisis política a la que viene enfrentándose nuestro país en los últimos años han dado impulso a las críticas que consideran que un sistema bipartidista como ha sido tradicionalmente el español en nuestra actual democracia, sobre todo, a partir tanto de la práctica desaparición de la Unión de Centro Democrático como de la pérdida de votos que sufrió el Partido Comunista de España, ambos como consecuencia de la victoria del Partido Socialista Obrero Español en 1982, favorece la falta de transparencia y la corrupción. Tales críticas se han traducido tanto en el recurso por parte de algunos colectivos a fórmulas de confrontación con el sistema, ajenas al sistema tradicional de partidos políticos e incluso ajenas a la democracia representativa, como en la aparición de nuevos partidos políticos con una representación parlamentaria ya algo relevante, como es el caso de Unión Progreso y Democracia, y a la recuperación del espacio perdido en los ochenta por la actual Izquierda Unida.

Así pues, no parece aventurado predecir ya un panorama en el que los dos grandes partidos necesiten acudir a una fórmula de pacto de gobernabilidad o, incluso, de gobierno de coalición, frente a la fórmula ya utilizada cuando alguno de ellos no accedía a la mayoría absoluta de simple apoyo político puntual en los partidos nacionalistas o regionalistas con presencia en el Parlamento, fundamentalmente Convergencia i Unió y el Partido Nacionalista Vasco. Estos, por sus propios orígenes, características y objetivos políticos, nunca han admitido incorporarse a la fórmula de un gobierno de coalición.

Ante tal tesitura, en la que podamos encontrarnos con un gobierno de coalición integrado por uno de los dos principales partidos y los dos minoritarios de ámbito nacional, Izquierda Unida y Unión Progreso y Democracia, resulta interesante plantearse qué puede ofrecer una fórmula como la implantada en 2011 en el Reino Unido.

Antes de ello, debemos recordar, desde la perspectiva meramente formal, que el Reino Unido, sobre la base de su constitucionalismo flexible, ofrece la posibilidad de reformar el sistema constitucional sin prácticamente sujetar dicha reforma a cánones formales $\mathrm{y}$, por tanto, de responder rápidamente, optando por una fórmula de reforma en sede parlamentaria sin sujeción a mayorías reforzadas. Frente a ello, nuestro sistema constitucional exigiría una reforma ordinaria, fundamentalmente, del artículo 113 de la Constitución dentro del marco procedimental recogido en el artículo 167, procedimiento éste algo menos complejo que el que consagra a continuación el artículo 168 pero que, en todo caso, mucho más difícil de alcanzar que la fórmula flexible británica. Así pues, una reforma como la introducida en la Cámara de los Comunes exigiría en el caso de España una mayoría de tres quintos.

Por lo que se refiere a los aspectos materiales de la reforma, la experiencia británica creemos que supone, a la postre, no una aproximación del modelo parlamentario británico al presidencialismo que se caracteriza por periodos de legislatura cerrados, sin posibilidad de anticipo electoral, sino más bien una racionalización del modelo y, por tanto, una continentalización de su parlamentarismo. A 
este respecto, puede recordarse que la principal diferencia en lo que a la moción de no confianza o censura entre el sistema Westminster y el racionalizado implantado en países como Alemania o España derivaba tanto de la mayoría parlamentaria exigida, ninguna en el primero hasta la reforma de 2011 y absoluta en el segundo, como de la exigencia de un candidato alternativo en el segundo, lo que convertía la votación de censura no sólo en una expresión de rechazo a un Canciller o Presidente de Gobierno, sino también en una manifestación de apoyo político al candidato alternativo. Se trata pues de un voto negativo y positivo conjuntamente, lo que lo hace más complejo en cuanto a los elementos a valorar en cada caso concreto.

Así pues, cabría plantearse si una fórmula con mayoría de dos tercios frente a la de mayoría absoluta promueve y facilita el gobierno de coalición, lo que desde una perspectiva puramente numérica puede entenderse que sí, ya que evitaría que el partido minoritario que proporciona la mayoría absoluta en el Congreso al mayoritario pueda romper fácilmente el acuerdo político y, sumando los votos de la oposición, no ya anticipar las elecciones, sino cambiar durante la legislatura de gobierno de coalición. Igualmente, elimina el poder del Presidente de Gobierno de emplear la disolución y convocatoria anticipada de elecciones como instrumento de presión sobre el partido minoritario con el que se ha conformado el gobierno de coalición.

Siendo ello cierto, no lo es menos que un correcto funcionamiento de los gobiernos de coalición, desde una perspectiva de Derecho comparado, no depende tanto de mecanismos legales formales, sino más bien de la existencia de una cultura política que acepte y promueva tales fórmulas de consenso. Sin dicha cultura, cualquier mecanismo que pretenda incentivar tales coaliciones de gobierno no ofrecerá más que un escenario más artificial que real, provocando, además, el peligro que tradicionalmente se aprecia en los sistemas presidencialistas del lame duck, es decir, un gobierno que se ve obligado a agotar una legislatura ya precipitadamente finiquitada. Ello puede ser usado, además, por el partido mayoritario en la oposición como instrumento de desgaste del gobierno, primando una vez más el interés partidista frente al general mediante el bloqueo de la elección anticipada.

Por ello, pudiera pensarse que la reforma adoptada en el Reino Unido más que alterar formalmente el modelo parlamentario en su fórmula tradicional Westminster, pretende impulsar una nueva forma de hacer política, más próxima a contextos en los que los intereses de los ciudadanos que integran la comunidad política se muestran más complejos y variados. Una comunidad en la que el acuerdo, el consenso y la coalición sean ya la solución natural y no la tradicional política británica de confrontación. Si la reforma se implantara en nuestro sistema constitucional como mecanismo impulsor de dicha nueva cultura, puede que ofrezca algunas soluciones para nuestro futuro. Si lo que se pretende, por el contrario, es tratar de conformar coaliciones de gobierno a largo plazo, sin verdadero ánimo y tradición por dichos consensos, puede que sea peor el remedio que la propia enfermedad. 
TITLE: Multiparty system in the british parliamen and the reform of the westminster model: an example (or a solution) for our own parliamentary party system in the future?

ABSTRACT: In 2011 the British Parliament approved, within the context of the coalition between the Conservatives and the Liberal Democrats, what can be seen as the most significant constitutional reform that the British government has undertaken in recent decades. This reform, called Fixed-term Parliament Act, 2011, restricts what was one of the main rights of the Prime Minister; dissolving the chamber in order to be able to call early elections. The reform is not motivated by an attempt to overcome the political crisis, similar to other European countries, that the UK is experiencing, but rather by the new demands that seem to derive from the current coalition government. It is certainly a reform that merits analysis by other nations, such as our own, in which fragmented parliaments are growing ever more likely, lacking strong majorities and posing problems that go beyond politics to the heart of the system.

Resumen: En 2011 el Parlamento británico aprobó, al amparo del acuerdo de coalición entre los conservadores y liberal-demócratas, la que puede considerarse la principal reforma constitucional a la que se ha visto sometido la forma de gobierno británica en las últimas décadas. Dicha reforma, bajo el nombre de Fixed-term Parliaments Act, 2011, supuso la supresión de una de las principales facultades del Primer Ministro, la de disolver la Cámara y convocar anticipadamente elecciones generales. Dicha reforma responde no tanto a la pretensión de superar la crisis política que vive el Reino Unido, similar a la que viven otros Estados europeos, sino a las nuevas exigencias que parecen derivarse del actual gobierno de coalición. En todo caso, se trata ciertamente de una reforma que merece la pena ser analizada desde otros Estados, como el nuestro, en los que se presagia un nuevo Parlamento muy fragmentado, sin mayorías de gobierno, con las consecuencias no sólo políticas que ello va seguramente a conllevar.

KeY words: British Parliament, House of Commons, Westminster Model, Constitutional Reform, multiparty systems, coalition government, calling early elections.

Palabras Clave: Parlamento británico, Cámara de los Comunes, modelo Westminster, reforma constitucional, multipartidismo, gobierno de coalición, convocatoria anticipada de elecciones.

FECHA DE RECEPCIÓN: 10.12.2014

FECHA DE ACEPTACIÓN: 04.02.2015 